\title{
LITERATURAS INDÍGENAS, ETNOTEXTO Y ORALITURAS: UN CORPUS EN CONSTANTE REDEFINICIÓN
}

\author{
LITTÉRATURES INDIGĖNES, ETNOTEXTE ET ORALITURES: \\ UN CORPUS EN RÉDEFINITION PERMANENT
}

\author{
Camilo Alejandro Vargas-Pardo ${ }^{1}$
}

\begin{abstract}
RESUMEN: Este artículo ${ }^{2}$ pretende enriquecer el debate sobre una historiografía literaria en Latinoamérica que ha privilegiado una concepción de la "literatura" tendiente a reproducir los prejuicios hegemónicos de la sociedad mayoritaria. A partir de un repaso comparativo por tres enfoques críticos relacionados con las nociones de "literaturas indígenas", "etnotexto" y "oralituras", se busca sintetizar diferentes propuestas de periodización de las expresiones literarias amerindias, visibilizando un corpus en constante redefinición. Se pretende destacar las particularidades de cada aproximación crítica como una forma de aportar al desarrollo de una historiografía literaria más inclusiva y consecuente a propósito de la diversidad en la que se manifiesta "la palabra" en una dimensión estética y cultural en este continente y, en particular, en Colombia. De este modo, se examina la aparición de las expresiones estéticas verbales de los pueblos originarios y del imaginario sobre "lo indígena" en el panorama literario colombiano.
\end{abstract}

Palabras clave: literaturas indígenas; etnotexto; oralituras; historiografía literaria.

RÉSUMÉ: Cet article cherche à enrichir le débat à propos d'une historiographie littéraire en Amérique Latine qui a privilégié une conception de la « littérature " où les préjugés hégémoniques de la société majoritaire se reproduisent. À partir d'un parcours comparatif sur trois regards critiques liés aux notions de "littératures indigènes ", "etnotexte " et "oralitures ", on cherche à synthétiser des modèles de périodisation des expressions littéraires amérindiens tout en remarquant un corpus en redéfinition permanent. Le but c'est de souligner les particularités de chaque modèle critique à fin d'apporter au développement d'une historiographie littéraire de plus en plus inclusive et conséquente par rapport à la diversité dans laquelle se présent "la parole", dans une dimension esthétique et culturelle, en ce continent et, en particulière, en Colombie. Ainsi, on examine l'apparition des expressions esthétiques verbales des peuples originaires et aussi de l'imaginaire sur "lo indígena " dans le panorama de la littérature colombienne.

Mots-clés: littératures indigènes; oralitures; etnotexte; historiographie littéraire.

ABSTRACT: This article tries to enrich the debate about a literary historiography in Latin America that has privileged a conception of "literature" tending to reproduce the hegemonic prejudices of the majority society. Starting from a comparative review of three critical approaches related to the notions of "indigenous literatures", "ethnotext" and "oralizations", the aim is to synthesize different proposals for periodization of Amerindian literary expressions, making visible a corpus in constant redefinition. It is intended to highlight the particularities of each critical approach as a way of contributing to the

\footnotetext{
${ }^{1}$ Doctor en Estudios Romances Españoles (CRIMIC - Université Sorbonne-Paris IV) y en Estudios Amazónicos (IMANI - Universidad Nacional de Colombia), en modalidad co-tutela internacional.

${ }^{2}$ Este artículo es una versión adaptada de un apartado de mi tesis doctoral: Poéticas que germinan entre la voz y la letra: itinerarios de la palabra a partir de las obras de Hugo Jamioy y Anastasia Candre (2019).
} 
development of a more inclusive and consistent literary historiography regarding the diversity in which "the word" is manifested in an aesthetic and cultural dimension on this continent and, in particular in Colombia. In this way, the appearance of the verbal aesthetic expressions of the native peoples and the imaginary about "the indigenous" in the Colombian literary scene is examined.

Keywords: Indigenous literatures; oralizations; ethnotext; literary historiography.

\section{Introducción}

Es común ver que cuando las historias literarias latinoamericanas incluyen expresiones de raigambre oral en su índice, tienden a resolver el problema de su ubicación remitiendo los textos relacionados con las tradiciones orales a un pasado prehistórico que no tiene ninguna resonancia en el presente. Ana Pizarro describe estas actitudes así:

Las limitaciones de estas proposiciones de solución de nuestra historiografía literaria, han sido, por una parte, el no reconocimiento de nuestra pluralidad cultural, refiriendo la literatura latinoamericana solo a la literatura del sector culto.

Por otra, estableciendo esta pluralidad como una secuencia en donde las literaturas indígenas son remitidas al pre-colombino, en términos de 'antecedente', que luego desaparece, absorbida en la legitimidad de una literatura de lengua metropolitana, la cultura canonizada de los sectores dominantes (PIZARRO, 1985, p.21).

Walter Mignolo, por su parte, interpela el ejercicio historiográfico en América Latina calificándolo de incipiente por el hecho de concentrarse en una concepción que privilegia la versión 'universal' de la historia, aquella que fue escrita por los europeos y que desconoce "las formas nativas de conservar el pasado" (2010, p. 129) de las culturas amerindias, así como las funciones del mito para preservar la memoria colectiva.

En efecto, la inclusión de las tradiciones orales amerindias en las historias literarias supone la revisión conceptual de lo que se comprende como 'literatura' en el campo de los estudios literarios y la historiografía literaria. Esta discusión es capital pues el discurso historiográfico define una determinada concepción de literatura desde donde se estabiliza un corpus y se le atribuye un contexto en el panorama literario. Generalmente este ejercicio consiste en asociar el texto a una procedencia nacional o establecer las delicadas fronteras entre géneros, épocas y tendencias. La historiografía literaria determina entonces la inclusión o marginación de áreas culturales, poblaciones, tendencias y discursos.

Al considerar las expresiones verbales estéticas de raigambre oral, criterios como el de la lengua y la nacionalidad, utilizados generalmente para organizar el discurso historiográfico, se tornan insuficientes y resultan cuestionados. De modo tal, establecer un panorama historiográfico que incluya las expresiones provenientes de la oralidad y los relatos fundacionales de las diferentes sociedades originarias puede resultar una tarea compleja.

Con la intención de llenar un vacío en el panorama literario colombiano, Héctor $\mathrm{H}$. Orjuela asumió la empresa de escribir la única historia literaria enfocada en las 'literaturas indígenas' de Colombia de la que hemos tenido noticia. Su libro Historia Crítica de la Literatura 
Colombiana. Introducción al estudio de las literaturas indígenas (2002) muestra un ejercicio riguroso de revisión de fuentes de distinta índole: textos coloniales, antropológicos, etnográficos, literarios y crítico-literarios, siguiendo una

metodología ecléctica e interdisciplinaria en la que se mezclan a los procedimientos comunes de la teoría y crítica literarias, la perspectiva de la oralidad, sesgos culturales pertinentes y análisis derivados de métodos etnográficos y antropológicos, con algún énfasis en el estudio de los mitos amerindios (ORJUELA, 2002, p.102).

Sin duda, este trabajo es una importante contribución para este campo de estudio, sin embargo, al discurrir por una gran diversidad de textos que orbitan el mundo indígena se proyecta una idea ambigua de "las literaturas indígena".

Surgen preguntas sobre la definición de la misma: ¿acaso es una serie de voces perdidas en el pasado precolombino de las cuales nos han quedado algunos vestigios arqueológicos?, ¿se trata de una serie de voces captadas por los misioneros y cronistas de la época colonial a través de la escritura alfabética?, ¿se refiere a los cantos y relatos transcritos por aventureros y antropólogos en su lengua original y traducidos al español u otras lenguas?, ¿se relaciona con los relatos de viajeros sobre encuentros interculturales con "tribus" desconocidas en el mundo occidental?, ¿se asocia con la descripciones etnográficas sobre etnias perdidas en la selva?, ¿comprende los mitos y leyendas de la tradición oral adaptados literariamente para un cierto público letrado?, ¿corresponde a aquellas novelas donde aparecen las costumbres, padecimientos o, en contados casos, voces de los indígenas?, ¿se refiere a lo relatos que se cuentan y a los cantos que se entonan en fiestas rituales o en la cotidianidad de los pueblos que las celebran?, ¿o se trata de poemas, cuentos y novelas escritos por autores que se identifican con un grupo étnico y escriben en sus lenguas nativas, al mismo tiempo que traducen su obra al español?

A continuación haremos un breve repaso de tres enfoques críticos que pueden ser útiles para reflexionar sobre estas preguntas. En este recorrido nos interesa sintetizar diferentes propuestas de periodización de las "literaturas indígenas' y, así mismo, revisar la aparición de las expresiones estéticas verbales de los pueblos originarios, así como del imaginario sobre "lo indígena”, en el panorama literario colombiano. De este modo, pretendemos evidenciar transformaciones significativas en la valoración de este tipo de fuentes, con lo cual se abren discusiones pertinentes en el seno de la crítica literaria. Así, buscamos contrastar algunas de las perspectivas que se han propuesto para abordar estos discursos, así como el modo en que han sido nombradas y las formas en que se han comprendido sus continuidades y rupturas. En este ejercicio resaltamos las diferencias de cada aproximación y procuramos sintetizar estas perspectivas críticas como una forma de aportar al desarrollo de una historiografía literaria cada vez más incluyente y menos eurocéntrica.

\section{Transcripción de mitos $=$ Literaturas indígenas}

En la investigación de Juan Adolfo Vázquez Literaturas indígenas de América. Introducción a su estudio (1999) se formula una clasificación de las "literaturas indígenas" en Latinoamérica que 
parte de la pregunta “ipero es que hubo realmente literaturas prehispánicas?” (1999, p.25). Con esta pregunta, este investigador de la Universidad de Pittsburgh, llama la atención sobre el dilema que sugiere la definición del conjunto de expresiones verbales simbólicas que existieron en Latinoamérica antes de la llegada de la escritura alfabética traída por los conquistadores españoles. Se repara entonces en la contradicción etimológica del término "Literaturas orales" para designar este conjunto, pero de otro lado se justifica el término "literaturas prehispánicas" insistiendo en aquellos discursos tradicionales que, logrando pasar al código escrito, se salvaron de las campañas de quema y destrucción de los "ídolos" llevada a cabo por los misioneros católicos.

Vázquez anota que la rigurosa definición de "lo literario" se concentra en formas y géneros circunscritos a la letra y no basta para describir el sentido de las "literaturas prehispánicas". Así, en un intento por ampliar el espectro de esta definición se refiere a la literatura como "algo fundado en la palabra y por accidente escrito con letras" (VÁZQUEZ, 1999, p.26).

Vázquez construye una mirada general de la llamada literatura indígena con una propuesta de periodización que recorre una línea histórica en la que las expresiones amerindias (a excepción del primer periodo denominado "Literaturas prehispánicas") son tenidas en cuenta, exclusivamente, gracias a su formato escrito. Se realiza así un recuento de esta "literatura" que inicia, como dijimos, con la categoría Literaturas prehispánicas; continúa con el periodo colonial con tres categorías: Primeras literaturas coloniales indias, Literatura española de principios de la época colonial y Literaturas indígenas de la época colonial posterior; y finalmente completa el recorrido en el periodo moderno en donde incluye las Literaturas indígenas modernas, las Literaturas folklóricas indígenas modernas y la Literatura indigenista hispanoamericana moderna.

En este punto, no sobra advertir que a lo largo de este artículo procuraremos ir señalando algunas referencias del heterogéneo corpus de las expresiones literarias amerindias en Colombia. Así, a partir de la clasificación de Vásquez haremos, a modo de ejemplo, algunas acotaciones referidas a los primeros periodos para ir situando el fenómeno de las literaturas indígenas desde un punto de vista centrado en el territorio colombiano

En la categoría Literaturas prehispánicas se incluyen diferentes formas de registro y comunicación que había antes de la llegada de los españoles. Sin detenerse mucho en la explicación de los códigos que menciona, el quipu $u^{3}$ entre los incas y los códices e inscripciones epigráficas entre las culturas mesoamericanas, comenta que pese a los numerosos hallazgos

\footnotetext{
${ }^{3}$ El quipu es considerado como una forma de escritura utilizada por los Incas a base de nudos hechos en un collar fabricado con cuerdas de colores. El Inca Garcilaso de la Vega se refiere a los quipus como la "manera de escribir que tuvieron los Incas en su república” (De la Vega citado por Niño en Poética indígena: Diáspora y retorno, p. 216). Para profundizar en los quipu andinos como forma de escritura consúltese los libros de Frank Salomon The Cord Keepers (2004) y Los Quipocamayos (2006). Por otro lado, en el artículo de Jean Pierre Chaumeil: "Khipu: ¿conexiones andino-amazónicas?” se propone la sugerente hipótesis de que los collares de dientes humanos utilizados entre diferentes grupos amazónicos, como objetos canalizadores de la memoria, guarda especiales vínculos con la tradición andina de los khipus o quipus. (véase Chaumeil, Jean Pierre, Óscar Espinosa de Rivero \& Manuel Cornejo Chaparro (Comps.) Por donde hay soplo: estudios amazónicos en los países andinos. Lima: IFEA, CAAAP, EREA LESC, 2011.)
} 
arqueológicos y al testimonio de sus piezas artísticas su mitología resulta lejana y difícil de comprender debido a la falta de registros escritos (VÁSQUEZ, 1999, pp.33-35).

A propósito del territorio que hoy en día conocemos como Colombia quisiéramos mencionar aquí los principales asentamientos arqueológicos. Como muestra de las numerosas formas de expresión de los pueblos originarios que poblaban este territorio se destacan las estatuas de San Agustín, los hallazgos en las necrópolis de Tierradentro y las impresionantes pinturas rupestres del Chiribiquete ${ }^{4}$, además de petroglifos, piezas de orfebrería, cerámica, tejidos, entre otros artículos de una notable factura estética que seguramente estaba relacionada con relatos fundacionales de las diferentes culturas.

Estos hallazgos arqueológicos cuestionan la noción falaz del "Nuevo Mundo", como una versión de la historia de tan solo 525 años, y se constituyen como una base documental en vivo diálogo con las tradiciones orales de los pueblos que hoy habitan dichos territorios. Según Arocha y Friedemann:

el mito como inspiración del arte indígena precolombino dejó plasmados en sus obras arqueológicas contornos, temas y símbolos que actualmente siguen representados en tradiciones orales, en la complejidad del parentesco de algunos grupos y naturalmente en el ritual religioso que asimismo se expresa plásticamente en traje, máscaras y adorno habitacional o en la talla de esculturas de madera. Y musicalmente, en la ejecución de instrumentos y el cántico que hace parte integral de la danza y del teatro en malocas, tambos y bohíos (AROCHA y FRIEDEMANN, 1985, p.50)

En segundo término, Vázquez propone la categoría Primeras literaturas coloniales indias, para referirse tanto a las producciones de escritores nahuas que adoptan el español como lengua de expresión literaria (Fernando Alvarado Tezozómoc, nieto de Moctezuma, es un ejemplo), así como a autores de ascendencia española e indígena como Felipe Guamán Poma de Ayala y el Inca Garcilaso de la Vega. Aquí se destaca la utilización del alfabeto latino en la elaboración de códices que registran la memoria cultural de las sociedades más expandidas a lo largo del continente, en este sentido se menciona el trabajo de Fray Bernardino de Sahagún para el caso náhuatl, reconocido por su trabajo en el Colegio de Santa Cruz de Tlatelolco en donde elabora junto con miembros de la élite Mexica lo que hoy conocemos como el Códice Florentino. Asimismo, aunque son casos completamente diferentes, se menciona a Diego de Landa, para el caso maya, y a Francisco de Ávila para el caso quechua, reconocidos como extirpadores de idolatrías que sin embargo se acercan a las lenguas indígenas con fines evangelizadores dejando un importante registro de mitos, cultos y leyendas (VÁSQUEZ, 1999, pp.35-37).

Enseguida, en la Literatura española de principios de la época colonial se ubican las cartas y crónicas que los conquistadores españoles redactaban con el objeto de informar sobre los hallazgos, -que podían ser objeto de saqueo- y los procesos de evangelización y colonización

\footnotetext{
${ }^{4}$ Carlos Castaño-Uribe en su artículo "Tradición Cultural Chiribiquete” referencia hallazgos arqueológicos datados con carbono C14 que van desde el 17.000 a.C hasta el siglo XVII d. C. Véase <http://www.rupestreweb.info/chiribiquete2.html> Consultado el 21/07/16
} 
del "Nuevo Mundo" -campañas de sometimiento, reducción y devastación cultural- (Ibíd., pp.3738).

Nos parece pertinente incluir algunas referencias literarias relacionadas con el desarrollo de las literaturas indígenas durante el periodo del Nuevo Reino de Granada. Encontramos, por ejemplo, el poema de Juan de Castellanos Elegías de Varones Ilustres de Indias (1589), las crónicas de Fray Pedro Simón Noticias historiales de las conquistas de Tierra Firme en las Indias Occidentales (1627), el Epitome de la conquista del Nuevo Reino de Granada, documento anónimo atribuido a Gonzalo Jiménez de Quesada ${ }^{5}$, la gramática chibcha de Fray Bernardo de Lugo Gramática en lengva general del Nuevo Reyno, llamada mosca (1619) y el Memorial de Agravios que en 1584 don Diego de Torres, el cacique de Turmequé, le destina al rey Felipe II en un caso similar al de Guamán Poma de Ayala.

La siguiente categoría Literaturas indígenas de la época colonial posterior se centra en textos transcritos en el transcurso del siglo XVI en lengua indígena a partir del alfabeto romano, como por ejemplo el Popol Vuh, los Libros del Chilam Balam, el Rabinal Achí, Los anales de los cakchiqueles, el Título de los señores de Totonicapán, el Güegüence o el drama Ollantay (Ibíd., pp.3840).

La siguiente categoría es Literaturas indígenas modernas, con la cual designa los trabajos que desde el siglo XIX se valen de informantes indígenas para grabar, traducir y transcribir sus tradiciones en colaboración con lingüistas y antropólogos. Resalta en ese sentido el rol del sujeto indígena como "informante" (Ibíd., pp.40-41). En este apartado sobresale un trabajo riguroso de revisión bibliográfica de las investigaciones que han compilado diferentes mitologías a lo largo de América Latina. Enseguida, con el título de Literaturas folklóricas indígenas modernas se describe una literatura que representa el mestizaje cultural, donde los rasgos de la antigua cosmovisión indígena subyacen en las modernas culturas mestizas de América Latina y se reconstruyen con un español que tiende a imitar la oralidad (Ibíd., pp.4143). En este apartado Vázquez también señala cierta estilización de las expresiones populares debido a la influencia e imposición de la gramática del castellano. Finalmente estaría la Literatura indigenista hispanoamericana moderna designando aquella literatura de autores modernos hispanoamericanos que, impregnados de tradiciones europeas, buscan presentar en español algunos aspectos de la vida indígena, tales como Miguel Ángel Asturias, José María Arguedas o Rosario de Castellanos. Estos autores, en general, dan al tema de lo indígena un tratamiento narrativo que se centra en el sujeto indígena como personaje, expresando el mestizaje de las culturas latinoamericanas o, como diría Rama, el fenómeno transcultural (Ibíd., pp.43-45).

En general, el trabajo de este investigador muestra que en efecto hay un corpus bibliográfico amplio que permite hablar de una "literatura indígena" en América; sin embargo, la intención de justificar y demostrar la existencia de una literatura indígena a través de la identificación de un corpus definido por el paradigma de la escritura, abre una perspectiva crítica sesgada en la que paradójicamente la oralidad, así como otras tecnologías de la memoria,

\footnotetext{
${ }^{5}$ Según la lectura de Carmen Millán de Benavides la autoría de este texto pertenece a Alonso de Santa Cruz (15051567). Véase su artículo: "Epítome de la conquista del Nuevo Reino de Granada" <http://revistas.javeriana.edu.co/index.php/univhumanistica/article/view/9569> Consultado el 22/07/16
} 
quedarían marginadas en la configuración de un corpus de estudio que se empeña en identificar "lo literario" tan sólo en todo aquello que está escrito a través del alfabeto latino.

Así, Vázquez privilegia una concepción que pareciera equiparar mito transcrito a literatura indígena. Antes de los años noventas esta perspectiva era común y detonó importantes cuestionamientos sobre el modo de abordar este tipo de expresiones desde un enfoque literario. Como se deduce de su propuesta de "mitoanálisis", Vázquez asocia el estudio estructural del mito al estudio de las literaturas indígenas modernas, buscando así un lugar para el análisis de estas expresiones en el campo de los estudios literarios, lo cual es interesante pero insuficiente. Su esquema de "mitoanálisis" se basa en la descomposición y revisión de unidades como acciones dramáticas, personajes, símbolos, contradicciones y transformaciones del relato mítico transcrito, con lo cual se atomiza y disecciona el relato, para comprender el nivel estructural de la narración; pero se descuida su función ligada a las creencias religiosas, las prácticas cotidianas, los festejos rituales y la vida cotidiana de un grupo humano determinado. De manera que con esta aproximación se pierde la singularidad del colectivo o de la persona que produce el relato ${ }^{6}$.

\section{Etnotexto: el resurgimiento de la oralidad}

La obra de Hugo Niño entreteje tres discursos en torno a las expresiones indígenas. Por un lado, desarrolla una propuesta literaria con un tono creativo que consiste en reescribir en español relatos míticos y leyendas de diferentes grupos indígenas del Amazonas que él ha escuchado de fuentes orales. De este modo, recrea varios relatos apoyándose en su propia sensibilidad literaria, los cuales reunió en Primitivos relatos contados otra vez (1976), obra con la que obtuvo por primera vez uno de los premios de Casa de las Américas.

En segunda medida, se aventura como compilador de un proyecto editorial que propició la valoración de las tradiciones orales en Colombia. Así, en 1978 publica la antología Literatura de Colombia Aborigen. En pos de la palabra donde compila narraciones orales recogidas por diferentes investigadores entre comunidades indígenas y afro-descendientes, tales como Roberto Pineda Camacho, Fernando Urbina, Milciádes Chavez, Martín Von Hildebrand, Nina S. de Friedmann, entre otros. Este trabajo reúne relatos mitológicos que son el resultado de aproximaciones etnográficas particularmente interesadas en la tradición oral donde el investigador funciona como mediador entre un "informante" -poseedor de la tradición oral-y el lector del libro.

Finalmente, recurriendo a un discurso de carácter crítico-teórico reflexiona sobre las expresiones orales aborígenes alrededor del concepto de etnotexto. Su conceptualización es divulgada en diferentes artículos académicos y reunida en su libro El etnotexto: las voces del asombro (2008).

\footnotetext{
${ }^{6}$ Por ejemplo, en una nota a pie de página se menciona la obra del escritor wayuu nacido en Venezuela Miguel Ángel Jusayú: "La atmósfera de los cuentos de Jusayú recuerda el mundo onírico de los mitos goajiros. Jusayú, que perdió la vista a los 13 años, revela un extraordinario poder de visión como escritor. También ha publicado una gramática y un diccionario de la lengua goajira” (VÁZQUEZ, 1999, p.103). Como puede verse la nota describe aspectos personales de gran interés que sin embargo no suscitan una reflexión sobre el sujeto indígena como autor literario, aspecto que resulta marginado a lo largo de su estudio.
} 
A continuación, presentamos dos propuestas de periodización de este autor destacando la complementariedad entre la una y la otra. La primera a que haremos referencia aparece en su libro El etnotexto: las voces del asombro (2008) y consta de tres momentos principalmente: un periodo temprano que cubriría el siglo XVI con "textos altamente contaminados, pero también de textos cuyos inscriptores, no obstante la censura a que debían someterse, fueron capaces de introducir claves y encriptamientos que hicieron posibles otras lecturas diferentes a las iniciales" (NIÑO, 2008, p.200), tales como el Rabinal Achí, Los libros del Chilam Balam, La Historia Quiché y el Popol Vuh. Un periodo medio que atravesaría el siglo XVII hasta el siglo XX, donde se mencionan autores como José Alcina Franch, Enrique de Gandia y Walter Krickeberg ${ }^{7}$, y en el cual "Las narraciones no son objeto de búsqueda y conocimiento como tales, sino que se acopian como material empírico para la etnografía, la lingüística y la historiografía cultural, como piezas de un pasado atávico" (Ibíd., p.202). Finalmente, propone un periodo de ruptura ubicado a partir de los años 1960s

cuando viene la irrupción de una literatura latinoamericana que se aparta de la propedéutica del buen narrar según el canon y se vuelca sobre sus propias cartografías invocando al mito como forma de conocer y contar, aun a riesgo de ser descalificada (Ibíd., p.203)

En este último se destacan diferentes trabajos antológicos como los de Jorge Zalamea Poesía ignorada y olvidada (1965), Ernesto Cardenal Homenaje a los indios americanos (1969), Jesús Lara: La literatura de los Quechuas: ensayo y antología (1961), Alfonso Torres Laborde: Mito y cultura entre los Barasana (1969), Carlos Alzate Giraldo: Latinoamérica Indígena: relatos y leyendas (1984), Guillermo Alberto Arévalo: Poesía indígena de América (1988), y el suyo propio Literatura de Colombia aborigen (1978) .

\footnotetext{
${ }^{7}$ Krickeberg publica en 1924 una de los primeras compilaciones de literatura indigena: Märchen dar azteken un inkaperuaner, maya and muisca (Mitos y leyendas de los aztecas, incas, mayas y muiscas)

${ }^{8}$ Con el ánimo de ampliar y complementar este panorama de trabajos antológicos incluimos las referencias de las que hemos tenido noticia. Literatura indigena americana, antología (1964) de Ernesto Cardenal y Jorge Montoya Toro ; Mitos leyendas y costumbres de las tribus suramericanas (1964) de María de Betania ; la Antología de poesía primitiva (1979) de Ernesto Cardenal; la Antología de creencias, mitos, teogonías, cosmogonias, leyendas y tradiciones de algunos grupos aborígenes colombianos (1973) de Fray Javier Montoya Sánchez; la Poesía de la América indigena (1980) de Héctor Orjuela ; la Poesía indigena de América (1988) prologada por Guillermo Alberto Arévalo ; La flor de la palabra (1984) de Victor de la Cruz; La producción literaria de los mayas contemporáneos (1997) y La oralidad en la literatura maya contemporánea (2006) de Jorge Miguel Cocom Pech; Womain. Poesía indigena y gitana contemporánea de Colombia (2000) de Juan C. Gamboa y Gregorio Moradas; la Antigua y Nueva Palabra, un antología de la literatura mesoamericana, desde los tiempos precolombinos hasta el presente (2004) de Miguel León Portilla y Earl Shorris ; Epu mari uikatufe ta fachantu“/ 20 poetas mapuche contemporáneos (2003), La memoria iluminada: poesía mapuche contemporánea (2007) y Antología de poesía indigena latinoamericana (2008) de Jaime Luis Huenún ; Kallfv Mapu. Tierra Azul (2008) de Néstor Barron; La tinta negra y roja: antología de poesía náhuatl (2008) de Coral Bracho; Hilando en la memoria (2009) de Soledad Falabella, Graciela Huinao y Roxana Miranda Rupailaf; Uk'u'x kaj, ik'u'x uleu: Antología de poesía maya guatemalteca contemporánea (2010) de Emilio del Valle Escalante ; La tinta negra y roja: antología de poesía náhuatl (2008) de Coral Bracho y Marcelo Uribe; Los escritores indigenas actuales (1992), La voz profunda. Antología de la literatura mexicana en lenguas indigenas (2004) y Palabras de los seres verdaderos. Words of the True Peoples (2005) de Carlos Montemayor; Sing. Poetry from the Indigenous Americas (2011) de Allison Hedge Coke; El dardo y la palabra. Poesía indigena de nuestra América (2007) de Alberto Rodríguez Carucci; Without Reservation. Indigenous Erotica (2003) de Kateri Akiwenzie- Damm ; Heart Mirror, el Espejo de Tierra (2008); The Willows Whisper: A Transatlantic Compilation of Poetry from Ireland and Native America de Jill M. O'Mahony; y el reciente Mensaje Indigena de Agua /
} 
Pese a que esta periodización resulta un tanto escueta, a partir de su artículo Poética indígena: diáspora y retorno (1998) se complementa su concepción de una "poética indígena" que se invisibiliza para luego reaparecer en diferentes manifestaciones. Este proceso es descrito a partir de tres momentos: 1) Exclusión y subalternización 2) Repliegue y enmascaramiento 3) Resurgimiento y trascendencia.

El primer momento está marcado por las estrategias de sometimiento cultural, en donde se destaca el uso de la Gramática de Nebrija como instrumento de dominación ideológica y esterilización de la lengua hegemónica. A esto se añade también la lectura del Requerimiento como imposición de un código cultural con el que se completaba la campaña para atentar contra la memoria cultural de los pueblos dominados a partir del exterminio de toda inscripción literaria indígena, como la quema de códices, quipus y la destrucción de los templos. Finalmente, se incluye como estrategia la creación de estereotipos, como el del caníbal, las Amazonas o El Dorado, como relatos que justificaban las incursiones militares y el desplazamiento forzado de la población.

Pese a que este primer momento describe las estrategias de acallamiento de las voces amerindias, no sobra un comentario sobre la resistencia de los wayúu en el Caribe colombiano. Niño hace hincapié en la confrontación bélica de un pueblo que no se sometió al esquema colonial, pero también cabría destacar que sus expresiones poéticas se entonan hoy en las rancherías de la Guajira, tanto en forma de cantos tradicionales como el jayeechi, como en los textos literarios que publican escritores autoidentificados con este grupo étnico, tales como Miguel Ángel López / Vito Apüshaina, Estercilia Simanca Puchaina, Vicenta María Siosi Pino, Rafael Mercado Epieyú, entre otros?

El segundo momento, de repliegue y enmascaramiento, "se presenta cuando la visión de los vencidos, para usar la figura de León Portilla, es enturbiada por la sombra del vencedor" (NIÑO, 1998, p.218) y está caracterizado por tres estrategias. En primer lugar, encontramos el "ocultamiento" como una forma de proteger relatos como el del Yurupari ${ }^{10}$, que guardan la memoria cultural de un pueblo y que frente a la contingencia del proceso de colonización dejan de circular y permanecen en secreto para aparecer luego bajo otras formas de expresión. En

Indigenous Message on Water (2014) de Juan Guillermo Sánchez M. y Felipe Quetzalcoatl.

9 Para nosotros es evidente que estos casos podrían incluirse en lo que Niño denomina "momento de resurgimiento y trascendencia”. Sobre la literatura wayúu véase la antología de Juan Duchesne-Winter: Hermosos invisibles que nos protegen. Antología Wayuu (2015), así como el trabajo de Gabriel Ferrer y Yolanda Rodríguez Cadena: Etnoliteratura Wayuu. Estudios críticos y selección de textos (1998)

${ }^{10}$ La leyenda del Yuruparí fue publicada en 1890 en el Bollettino della Societá Geografica Italiana por el conde Ermanno Stradelli. El relato había sido recogido y transcrito en caracteres latinos en Lengua general (el ñe'éngatú es una lengua que se deriva del Tupí antiguo, adaptada y difundida por las primeras misiones que se instalaron en la zona) por el indígena Maximiano José Roberto, quien legó sus manuscritos al explorador italiano. Juntos habían recorrido las corrientes de río Vaupés deteniéndose en los petroglifos para rastrear la historia del Yuruparí. El relato cuenta la historia del héroe civilizador que instituye las sagradas leyes del Yuruparí restituyéndole a los hombres el poder que había sido tomado por las mujeres. Esta tradición mítica está asociada al rito de iniciación masculina celebrado actualmente por numerosos grupos indígenas del noroeste amazónico. Véase Luis Cayón, 2002, En las aguas del Yuruparí, Bogotá, Universidad de los Andes; Ariel José James (Comp.), 2002, Mito tucano del origen del hombre, Bogotá, Zahir; Héctor Orjuela, 1983, Yurupary: mito, leyenda y epopeya del Vaupés, Bogotá, Instituto Caro y Cuervo; Gerardo Reichel-Dolmatoff, 1983, Yuruparí. Studies of an Amazonian Foundation Myth. Harvard, Harvard University Press. 
segundo lugar, aparece "el sincretismo", asimilado al concepto de transculturación acuñado por Fernando Ortiz, y atribuido también al caso de las comunidades afro-descendientes, como una forma de "enmascarar la textualidad bajo la ritualística cristiana" (NIÑO, 1998, p.218). Una tercera estrategia de ocultamiento estaría vinculada al "indigenismo literario", una corriente literaria enmarcada en el Realismo y Naturalismo de principios del siglo XX donde el indio aparece como un elemento decorativo y exótico.

(Aprovechamos este punto para incluir un breve paréntesis sobre la narrativa colombiana. Aunque generalmente ésta no es incluida por la crítica literaria dentro del espectro indigenista y sobresalen en cambio categorías más amplias como "novela telúrica" o "terrígena", quisiéramos destacar tres obras que en su momento llamaron la atención sobre las tremendas injusticias cometidas en la época de las caucherías contra diferentes grupos indígenas amazónicos $^{11}$. La reconocida novela de José Eustasio Rivera La vorágine (1924) y la de Cesar Uribe Piedrahita Toá. Narraciones de caucherias (1934) describen las crueldades a las que eran sometidos los indígenas con el sistema de endeudamiento creado por los caucheros peruanos para esclavizarlos. El texto del nariñense Julio Quiñones Au ceour de l'Amérique vierge (1924), anunciado como un relato de su vivencia entre los nonuya en el Amazonas colombiano, se acerca al punto de vista indígena describiendo el universo cultural de este grupo y anunciando el riesgo de su desaparición ${ }^{12}$ ).

El tercer momento, llamado de resurgimiento y trascendencia, está asociado con el concepto de "etnotexto": "En Colombia la irrupción en territorios culturales más allá de los límites, la presencia del etnotexto como una expresión de contestación frente a la noción de 'unidad' cultural, de 'identidad' nacional, se sitúa a mediados de los años setenta" (NIÑO, 1998, p.221), se refiere a textos que tienden a contra-restar la idea hegemónica de 'cultura' heredada desde los tiempos de la colonia, con la cual se fijaba la atención en Europa como modelo a seguir, rindiéndole así culto a la letra escrita y a la llamada cultura letrada. Para la antropóloga colombiana Nina de Friedemann, que concentró sus investigaciones en las tradiciones orales de las comunidades afro en Colombia, el concepto "oralitura", acuñado por el historiador africano Yoro Fall, se emparenta con el concepto de "etnotexto":

La representación que Niño ha denominado etnotexto, desde mi propia apreciación, siguiendo a Yoro Fall (1992) ha tomado piezas de oralitura, es decir expresiones estéticas de la oralidad, de una tradición étnica, las cuales debieron transferirse a la escritura para luego realizar una nueva elaboración estética escrita (FRIEDEMANN, 1999, p. 25).

En todo caso, desde su origen ambos conceptos buscan desestabilizar la noción

\footnotetext{
${ }^{11}$ Las primeras publicaciones que se encargaron de denunciar el holocausto de las caucherías cometidas por la Casa Arana en el Amazonas fueron los textos del americano Walter Hardenburg "El paraíso del Diablo. Un Congo con dueños británicos" (1909) publicado por el diario londinense Truth; los informes encargados por el gobierno británico del irlandés sir Roger Casement El libro azul del Putumayo (1912) y El libro rojo del Putumayo (1912). Por otro lado, la etnografía de Tohmas Whiffen The Northwest Amazon. Notes of some months spent among cannibal tribes (1915) sirvió como base documental para iniciar una investigación contra la Casa Arana.

${ }^{12}$ Véase Alexis Uscátegui Narváez. "En el corazón de la América virgen” de Julio Quiñones. Una alternativa en la novelística colombiana. Estudios de literatura colombiana, No 39, pp. 61-77, 2016.
} 
dominante y hegemónica de literatura. Para concluir, podemos decir que su concepción de "etnotexto" ha favorecido la descripción y el reconocimiento del arte verbal aborigen, inserto en esferas de expresión colectiva y en algunos casos ritual, como aportes de la expresión humana al campo artístico y cultural. Su trabajo favorece una concepción de cultura nacional más plural y diversa, pero su énfasis está volcado principalmente en las versiones que hacen los investigadores en sus trabajos etnográficos sobre el arte verbal. En su perspectiva no aparecen aquellos sujetos que se identifican como indígenas y dinamizan sus obras colectivas o personales, tanto como su visión de mundo en los circuitos culturales de la sociedad dominante en tanto autores.

\section{El periodo oraliterario: continuidad y renovación de la tradición}

En la última década se ha hecho notorio un cambio de actitud frente a la voz indígena. Una muestra de ello son dos proyectos editoriales que surgieron en el año 2010, año en que fue impulsada por el Ministerio de Cultura de Colombia la Biblioteca Básica de los Pueblos Indígenas de Colombia y la antología Püchi Biyá Uai. Antología multilingüe de la literatura indígena contemporánea en dos tomos, la cual circuló en la colección Libro al viento promovida por la Alcaldía Mayor de Bogotá.

De este modo, aquellas voces que han sido silenciadas y menospreciadas durante siglos, han podido visibilizarse a través del formato del libro al mismo tiempo que resuena su palabra poética en calidad de textos literarios. En este sentido el trabajo compilatorio e investigativo de Miguel Rocha Vivas ha contribuido a reconocer un panorama de la literatura indígena en Colombia en el que se destaca la producción literaria de varios autores indígenas.

No obstante, este investigador reconoce que en este panorama hay principalmente un corpus "etnoliterario" en el que los indígenas que contribuyen en la construcción de textos relacionados con su tradición oral quedan siempre al margen de la escritura.

Etnoliteratura, o literatura étnica oral transcrita, es concretamente la que en Colombia está plasmada en grandes obras etnográficas que han servido para diversos fines, los cuales pueden apreciarse en el interés de un selecto grupo de intelectuales predominantemente europeos o de formación europea, quienes han coincidido en el heterogéneo proyecto de estudiar las lenguas y el pensamiento indígena. (...) En fin, el actual gran corpus de la llamada literatura indígena en Colombia es básicamente etnoliterario; esto quiere decir que es resultado de la participación pasiva y /o de la cooperación activa de narradores, cantores y pensadores indígenas, principalmente a modo de informantes, colaboradores y excepcionalmente coautores (ROCHA, 2010a, pp.51-52).

Con todo, Rocha insiste en el reconocimiento de autores que se identifican como indígenas y cuyas elaboraciones poéticas son portadoras de símbolos y significados de gran trascendencia para sus colectividades. En su investigación Palabras mayores, palabras vivas. Tradiciones mítico-literarias y escritores indígenas en Colombia (2010) Miguel Rocha Vivas propone una periodización de las literaturas indígenas que se complementa con una "Cronología continental" en la que se procura estabilizar un corpus describiendo las publicaciones 
relacionadas con las expresiones amerindias. Los cuatro periodos propuestos por Rocha son los siguientes.

Un periodo precolombino del que tenemos referencia a través de algunas crónicas: "infinidad de escrituras tradicionales (pinturas y petroglifos rupestres; tejido; objetos de oro, tumbaga, concha, madera y hueso; esculturas; cerámica pintada y moldeada, etc.) y múltiples continuidades culturales de tradición ritual oral” (Ibíd., p.53).

Un período crónico centrado en los años de la colonia, donde se incluyen cronistas de indias, líderes indígenas y mestizos que hacían reclamos mediante cartas a la corona y otras voces. Aquí también se incluye el periodo transicional hacia la República durante las primeras décadas del siglo XIX donde "Los viajeros pioneros de la mirada científica europea sobre lo indígena fueron en realidad un nuevo tipo de cronistas" (Ibíd., p.53).

El periodo etnoliterario caracterizado por la influencia de la mirada etnográfica y etnolingüística, en la que hay informantes y colaboradores indígenas que facilitan la publicación bilingüe. En este periodo también se habla de etnoliteratura propia, que sería el caso en el que los mismos indígenas adelantan procesos similares con fines antropológicos o comunitarios, en tanto cartillas educativas, planes de vida, entre otros.

Habría que señalar también que este último se desarrolla de manera simultánea al periodo oraliterario. En este último, afirma Rocha, "surgen y se visibilizan los escritores escritoras indígenas en sí, a manera de autores de identidad colectiva que suelen resaltar su vinculación con el arte verbal oral de sus comunidades y de sus mayores" (Ibíd., p.55).

Ahora bien, detengámonos con más calma en los dos últimos. En la "Cronología continental" el periodo etnoliterario se inaugura con la publicación del Yurupari del conde Ermanno Stradelli en 1890 y se extiende hasta nuestros días, ya que para este autor se desarrolla simultáneamente con el periodo oraliterario. Si bien se centra en la mirada etnográfica, podemos constatar que este periodo abarca diferentes tipos de discursos relacionados con el mundo indígena: surgen antologías, testimonios y novelas de tema indígena (Krickerberg, KochGrünbmerg, Walter Handerburg, Roger Casement, Thomas Whiffern, Julio Quiñones, Jose E. Rivera, Cesar Uribe Pidrahita, Cardenal, Zalamea, entre otros ${ }^{13}$ ).

Naturalmente, también hallamos trabajos concentrados en las tradiciones orales como la impresionante compilación de Konrad Theodor Preuss publicada originalmente en uitoto (mika) y alemán: Religion und Mythologie der Uitoto. Textaufnahmen und Beobachtungen bei eiken Indianerstamm in Kolumbien, Südamerika (1921-1923), el cual es reeditado en 1994 en versión bilingüe uitoto (mika) - español, tras la revisión del uitoto hecha por Eudocio Becerra y Gabriele Petersen. Cabe mencionar otros trabajos de esta índole relacionados con el Amazonas, tales como la investigación entre los andoque realizada por Roberto Pineda Camacho y John Landabouru Tradiciones de la Gente del Hacha (1986) y los trabajos de Fernando Urbina Rangel relacionados con la tradición oral uitoto Mitología amazónica: cuatro mitos de los murui muinanes

\footnotetext{
${ }^{13}$ Por otro lado, en este periodo son numerosas las publicaciones del Instituto Lingüístico de Verano relacionadas con las lenguas indígenas. Esta entidad perteneciente al cristianismo protestante tiene como principal misión traducir la Biblia a las lenguas indígenas con fines evangélicos. La educación en las regiones más alejadas del país fue contratada con el ILV durante cuarenta años desde 1962 en el gobierno de Alberto Lleras Camargo, con lo cual el patrimonio cultural y lingüístico del país quedó en manos de una entidad de carácter misional y evangélico.
} 
(1982) y Las palabras del origen. Breve compendio de la mitología de los Uitotos (2010).

Según Rocha en este periodo también surge una etnoliteratura propia, que sería el caso en el que los mismos indígenas adelantan proceso de recopilación, transcripción y traducción de sus tradiciones orales con fines antropológicos o comunitarios, divulgados en forma de cartillas educativas, planes de vida, mapas, entre otros.

Asimismo, en este periodo aparecen una serie de voces indígenas que podríamos tildar como "precursores" o autores bisagra entre el periodo etnoliterario y oraliterario: Manuel Quintín Lame (1880-1967) favoreció la lucha por el reconocimiento de los territorios ancestrales indígenas e inspiró la organización del movimiento de resistencia indígena del Cauca con sus textos de corte reivindicatorio y tono político como Los pensamientos del indio que se educó dentro de las selvas colombianas (redactada en 1939 y publicada hasta 1971). Antonio Joaquín López (1897 - 1989), conocido como Briscol, publica Los dolores de una raza, novela histórica de la vida real contemporánea del indio guajiro (1956), "considerada hasta el presente como la primera novela de un escritor indígena nacido en Colombia" (Rocha, 2010b, p.156). Alberto Juajibioy Chindoy (1920 - 2007), consagrado a la investigación de su lengua y cultura camëntsá, cuenta con varias publicaciones, entre ellas: Breve estudio preliminar del grupo aborigen del Sibundoy y su lengua kamsá en el sur de Colombia (1962), Relatos ancestrales del folclor camëntsá (1989) y Lenguaje ceremonial y narraciones tradicionales de la cultura kamëntsá (2008). Francelina Muchavisoy (1965), de origen Inga y autora de varios poemas; entre otros.

Por otro lado, el periodo oraliterario, se sitúa teniendo como marco el surgimiento de la nueva constitución que reconocía el país como un estado pluriétnico y multicultural de Colombia, en $1991^{14}$. A continuación, nos permitiremos describir los dos proyectos editoriales que coordina este investigador. En 2010 fue impulsada por el Ministerio de Cultura de Colombia, en el marco de la celebración del bicentenario de la independencia, la Biblioteca Básica de los Pueblos Indígenas de Colombia ${ }^{15}$. Esta colección consta de 8 ejemplares; entre estos hay un tomo de corte histórico: Documento para la historia del movimiento indígena Colombiano realizado por Enrique Sánchez Gutiérrez y Hernán Molina Eheverry; dos tomos de corte antológico realizados por Miguel Rocha Vivas; uno, Antes el amanecer, que recopila literaturas indígenas de los Andes y la sierra nevada de Santa marta; y el otro, titulado El sol babea jugo de piña, donde encontramos literaturas indígenas del Atlántico, el Pacífico y la serranía del Perijá. El cuarto tomo es concebido como compendio de la mitología de los Uitotos, Las palabras del origen, realizado por Fernando Urbina Rangel. A continuación contamos tres tomos más que son obras poéticas de escritores indígenas. Estos últimos se presentan de este modo: el quinto tomo es dedicado al escritor wayuu Miguel Ángel López titulado Shinalu'uirua shiirua ataa / En la hondonadas maternas de la piel, publicado bajo su heterónimo Vito Apüshana; el sexto, al escritor camëntsá Hugo Jamioy Juagibioy titulado:

\footnotetext{
14 Para complementar véase: Miguel Rocha Vivas. Oralituras y literaturas indígenas en Colombia: de la constitución de 1991 a la Ley de Lenguas de 2010. A contra corriente. Una revista de historia social y literatura de América Latina. Vol 10, No 3, pp 74-107, Spring 2013.

${ }^{15}$ En esta dirección web es posible descargar los ocho tomos que hacen parte de la Biblioteca Básica de los Pueblos Indígenas de Colombia: http://www.banrepcultural.org/blaavirtual/biblioteca-indigena-colombia
} 
Bínÿbe Oboyejuayëng / Danzantes del viento; y el séptimo reproduce el último trabajo poético del escritor yanakona Fredy Chikangana: Samay piscok pponccopi mushcoypa / Espiritu del pájaro en pozos del ensueño, quien suele publicar bajo el seudónimo de Wiñay Mallky. Para cerrar esta colección se publica el octavo tomo: un Manual introductorio y guía de animación a la lectura; una aproximación didáctica a esta literatura puesto que la colección, que no tiene fines comerciales, está dirigida principalmente a centros educativos.

Podemos decir que es una colección que resalta la idea de la autoría indígena, y en este sentido es notoria la intención de hacer escuchar no sólo las voces de los investigadores interesados en el mundo indígena, sino también las voces de varios escritores que se identifican con una nación indígena. Sobresalen tres autores merecedores de premios literarios, con cierta proyección a nivel nacional e internacional.

Miguel Ángel López publica en wayuunaiki y en español bajo los heterónimos de Malohe y Vito Apüshana y sus obras más conocidas son Contrabandeo sueños con alijunas cercanos (1992) y Encuentros en los senderos de Abya Yala (2000), con la cual ganó el premio Casa de las Américas en la categoría de poesía en el año 2000.

Por su parte, Fredy Chikangana obtuvo en 1993 su primer reconocimiento con el premio "Humanidad y Palabra" otorgado por la Universidad Nacional de Colombia y en adelante ha publicado sus poemas en reconocidas revistas literarias nacionales e internacionales. Chikangana aprendió quechua con el interés de consolidar en esta lengua su poética y así en 2008 publicó bajo el seudónimo de Wiñay Mallky su libro Kentipay llattantutamanta / El colibrí de la noche desnuda, traducido al italiano en 2010. Posteriormente publicó el título que aparece en la Biblioteca: Samay Piccok pponccopimushcoypa / Espíritu del pájaro en pozos del ensueño.

Hugo Jamioy Juagibioy obtuvo en 2006 la Beca Nacional de Investigación en Literatura del Ministerio de Cultura de Colombia, experiencia tras de la cual promueve la primera convocatoria de las Becas de Creación en Oralitura de este Ministerio. En 2009 obtiene una de las dos becas de creación en oralitura con su proyecto Hablando junto al fogón, en el que se combina el video y la creación literaria. En esta colección aparece una edición ampliada de su libro Binÿbe Oboyejuayëng / Danzantes del viento, cuya primera edición aparece en 2005. Sus poemas han sido publicados en revistas universitarias y antologías de escritores en lenguas indígenas en diferentes países.

El segundo proyecto editorial al que queremos hacer referencia sale a la luz el mismo año (2010) en la colección Libro al Viento, promovida por la Alcaldía Mayor de Bogotá. Se trata de la antología Püchi Biyá Uai. Antología multilingüe de la literatura indígena contemporánea en dos volúmenes: vol.1: precursores y vol. 2: puntos aparte. Editada por Rocha Vivas, esta antología incluye tan sólo autores que se reconocen como pertenecientes a una nación indígena. Además de Miguel Ángel López / Vito Apüshana, Fredy Chikangana / Wiñay Mallky y Hugo Jamioy Juajibioy, nos encontramos con un panorama un poco más amplio en el que se identifican como "precursores" autores como: Antonio Joaquín López, Alberto Juajibioy Chindoy, Miguel Ángel Jusayú, Esperanza Aguablanca (conocida por el seudónimo de Berichá). También encontramos en el segundo volúmen, subtitulado "puntos aparte", a autores como Anastasia Candré Yamacuri, quien publicaba por primera vez sus poemas, así como Vicenta 
María Siosi Pino, Yenny Muruy Andoque, Estercilia Simanca Pushaina y Efrén Tarapués Cuaical.

Estas publicaciones testimonian un claro interés institucional por visibilizar la producción literaria indígena como parte del acervo cultural que el estado colombiano, bajo sus políticas culturales, debe salvaguardar ${ }^{16}$. El 2010 se constituye así en un año en que el fenómeno de la literatura indígena en Colombia se visibiliza, permitiendo así que las voces indígenas, generalmente menospreciadas en el plano de literatura colombiana, se apropien de un espacio que las difunde en el mundo letrado y abre puertas de diálogo con la sociedad mayoritaria.

Ahora bien, en el periodo oraliterario nos parece oportuno distinguir diferentes tipos de textos, proponiendo algunos ejemplos. Encontramos textos de autoría indígena individual como los que hemos venido señalando a propósito de las publicaciones descritas y entre quienes cabría agregar a Abadío Green / Manibinigdiginya (kuna-tule), Aniceto Nejedeka / Numeyí (muinane), Oscar Román / Enókakuiodo y Ángel Kytoteca Jifikomui (uitotos), Yenny Muruy Andoque / Yìche (andoque - uitoto), entre otros. También encontramos proyectos editoriales de autoría colectiva, como por ejemplo las publicaciones de la editorial Terra Nova donde encontramos cantos uitoto, cocama, yagua y tikuna, interpretados por diferentes miembros de cada comunidad, los cuales son grabados en CD, transcritos y traducidos al español; el libro de la Asociación de Capitanes y Autoridades tradicionales Indígenas del río Pirá Paraná (ACAIPI) Hee Yaia Godo-Bakari. El Territorio de los Jaguares de Yurupari. Conocimiento tradicional de las etnias del rio Pirá Paraná para el manejo del Medio Ambiente (2015); o el libro Fééne fíwo játyime iyáachimihai jínitje. Territorio primordial de vida de la gente de Centro (2016). Podríamos hablar también de textos de co-autoría en colaboración intercultural como Tabaco frío y coca dulce (1993) de Hipólito Candre / Kineraì y Juan Álvaro Echeverri, o Mágutà: la gente pezcada por Yoi de Hugo Camacho en colaboración con varios sabedores tikuna: Manduca López Abeca, Francisco Fermín Bautista, Jorge Manduca María, Federico José Huaines, Juana Agusto Dionicio y Margarita Julián. Finalmente podríamos hablar de textos escritos por un escritor no indígena desde una perspectiva indígena como Diijoma, el hombre-serpiente-aguila (2004) de Fernando Urbina, Cuentos amazónicos (2007) de Juan Carlos Galeano y algunas obras de Flor Romero.

Para concluir podemos decir que la propuesta de periodización de Miguel Rocha Vivas se diferencia de las anteriores, por un lado, porque la tradición oral no está desdibujada en un pasado incógnito sino que, al contrario, se repara en su vigencia en el mundo contemporáneo y, en especial, en las apuestas estéticas de autores que reivindican los vínculos entre sus producciones literarias y la oralidad de sus pueblos, advirtiendo, de este modo, sobre las posibles continuidades de la palabra y el pensamiento amerindio desde antes de la llegada de los europeos hasta ahora. Por otro lado, se propone una categoría que surge de la iniciativa del poeta mapuche Elicura Chiuailaf al reconocerse como "oralitor", a la cual se adhiere un grupo

\footnotetext{
${ }^{16}$ Es importante insistir en que tan sólo hasta la reforma constitucional de 1991 en Colombia se reconoce por primera vez el carácter "pluriétnico y multirultural" de la sociedad colombiana, lo cual influye en la políticas culturales, territoriales y educativas, a favor de las minorías étnicas. Con esta base legislativa se creo hasta el 2010 la ley de lenguas que define las medidas del Estado para proteger el patrimonio y la diversidad lingüística de Colombia.
} 
de autores indígenas contemporáneos colombianos que aluden en sus obras a su herencia cultural procedente del mundo oral a través de una exploración de temáticas y "textualidades oralitegráficas" comprendidas como textos poéticos donde se reafirman y redefinen subjetividades. En diálogo con los autores indígenas este investigador propone la noción de "textualidades oralitegráficas" como un aporte que nos llama a reconsiderar los discursos historiográficos que construyen una mirada sesgada de la historia y constriñen las memorias colectivas al privilegiar el ejercicio de la memoria mediante la escritura alfabética. Como vemos, Rocha aboga por ampliar esta perspectiva:

"En síntesis, las textualidades oralitegráficas son intersecciones textuales entre diversos sistemas de comunicación oral, literaria y gráfica-visual. En algunas obras las intersecciones se producen entre lenguajes visuales-provenientes de sistemas gráficos como la textilería o la alfarería-; producciones alfabéticas bilingües-o en un castellano con gran número de préstamos de determinadas lenguas indígenas-; y experimentaciones, continuidades y/o recuperaciones de artes verbales orales como el haylli (himno elegíaco quechua) o el botamán biyá (palabra bonita camëntsá)" (Rocha, 2016, pp. 22-23).

\section{A modo de conclusión}

Las diferentes propuestas de periodización de las expresiones literarias amerindias que hemos revisado convergen en el interés de resaltar la existencia de un corpus consistente que no ha sido lo suficientemente visitado por la crítica literaria.

Cada uno de los investigadores propone un término que caracteriza su posición frente al fenómeno estudiado y, a su vez, devela los sesgos interpretativos de la misma. Así, Héctor Orjuela y Juan A. Vázquez coinciden en denominar este corpus como "literaturas indígenas" desde una concepción de literatura que privilegia aquellas fuentes que pasan por la escritura alfabética. Hugo Niño propone el concepto de "etnotexto" reivindicando las particularidades ético-estéticas de la performancia oral; sin embargo, su estudio se afianza en las recopilaciones del arte verbal hechas desde la antropología. Miguel Rocha Vivas propone la noción de "oralitura" poniendo énfasis en los autores que se identifican con naciones indígenas y crean propuestas literarias a partir de su legado cultural. La noción de "textualidades oralitegráficas" de Rocha tiende a descentrar la hegemonía de la letra escrita y las lenguas mayoritarias a través de exploraciones estéticas de autores indígenas que sobrepasan la expresión mediante la escritura alfabética.

Podríamos deducir que la intensión de descentrar y ampliar el corpus "oficial" de la literatura en latinoamericana ha llevado a algunos investigadores -como a los que hemos apelado en este artículo- a construir aproximaciones teórico-críticas que nos llevan a interpelar los paradigmas que han establecido una concepción grafocéntrica de la literatura en donde las tradiciones orales resultan siempre relegadas o no tienen cabida. Desde esta perspectiva se desestabiliza el panorama historiográfico de la literatura latinoamericana enfocado en la producción de textos escritos.

En este sentido, al constatar que nuestra historia está marcada por una serie de intercambios culturales asimétricos en los cuales la escritura ha sido utilizada como instrumento 
de control que generó la marginación de los sistemas de comunicación de poblaciones aborígenes y afro-descendientes, y además, que en el campo de los estudios literarios existe un desconocimiento casi total de las tecnologías de la memoria y de los géneros discursivos que aún hoy existen entre los pueblos originarios (así como de sus cualidades, recursos estéticos y de los saberes que éstas palabras guardan), cabe preguntarnos si es posible imaginar una historiografía y una crítica literarias capaces de construir una mirada más incluyente en donde se integre y reconozcan las relaciones -en las mayoría de casos conflictivas- entre la gran diversidad de voces que configuran, crean y recrean, las memorias de los pueblos latinoamericanos y del Abya-Yala.

\section{Referencias}

AROCHA, J.; FRIEDMANN, N. Herederos del jaguar y la anaconda. Bogotá: Carlos Valencia Editores, 1985.

CHAUMEIL, J. P.; ESPINOSA DE RIVERO, Ó.; CORNEJO CHAPARRO, M. (Comps.) Por donde hay soplo: estudios amazónicos en los países andinos. Lima: IFEA, CAAAP, EREA LESC, 2011.

FRIEDMANN, N. De la tradición oral a la etnoliteratura. Oralidad, No 10, pp. 19-27, 1999.

MIGNOLO, W. La historiografía incipiente: formas de la memoria en las tradiciones amerindias y en la tradición europea. In: PUCCINI, D; YURKIEVICH, S. (Comps.), Historia de la cultura literaria en Hispanoamérica I, México D.F, Fondo de Cultura Económica, 2010.

NIÑO, H. Poética indígena: diáspora y retorno. Cuadernos de Literatura, Vol 4, No 7 - 8, pp. 213-228, ene - dic, 1998.

NIÑO, H. El etnotexto: las voces del asombro. La Habana: Fondo Editorial de la Casa de las Américas, 2008.

ORJUELA, H. Historia Crítica de la Literatura Colombiana. Introducción al estudio de las literaturas indígenas. Bogotá: Editorial Guadalupe, 2002.

PIZARRO, A. (Coord.) La literatura latinoamericana como proceso. Buenos Aires: Bibliotecas Universitarias, Centro Editor De América Latina, 1985.

ROCHA VIVAS, M. Palabras mayores, palabras vivas. Tradiciones mítico-literarias y escritores indígenas en Colombia. Bogotá: Fundación Gilberto Alzate Avendaño (Premio Beca Nacional de Investigación en Literatura), 2010a.

ROCHA VIVAS, M. Püchi Biyá Uai, Precursores: Antología multilingüe de la literatura indígena contemporánea en Colombia (Vol.1). Bogotá: Fundación Gilberto Alzate Avendaño, 2010b.

ROCHA VIVAS, M. Püchi Biyá Uai, Puntos Aparte: Antología multilingüe de la literatura indígena contemporánea en Colombia (Vol.2). Bogotá: Fundación Gilberto Alzate Avendaño, 2010c.

ROCHA VIVAS, M. Oralituras y literaturas indígenas en Colombia: de la constitución de 1991 a la Ley de Lenguas de 2010. A contra corriente. Una revista de historia social y literatura de América Latina. Vol 10, No 3, pp. 74-107, Spring 2013.

ROCHA VIVAS, M. Mingas de la palabra. Textualidades oralitegráficas y visiones de cabeza en las oralituras y literaturas indígenas contemporáneas. La Habana: Casa de las Américas (Premio Casa de Las Américas en 2016 en la categoría Estudios sobre Culturas Originarias de América), 2016. 
USCÁTEGUI NARVÁEZ, A. En el corazón de la América virgen de Julio Quiñones. Una alternativa en la novelística colombiana. Estudios de literatura colombiana, No 39, pp. 61-77, 2016.

VÁZQUEZ, J. A. Literaturas indígenas de América. Introducción a su estudio. Barcelona: Azul Editorial, 1999.

Recebido em: 17/03/2020

Aceito em: 29/03/2020 